\title{
EL RESTABLECIMIENTO TEMPORAL DE CONTROLES EN LAS FRONTERAS INTERIORES DE LA UNIÓN EUROPEA COMO RESPUESTA A LAS AMENAZAS AL ORDEN PÚBLICO Y A LA SEGURIDAD INTERIOR: ENTRE LA EXCEPCIONALIDAD Y LA NORMALIDAD
}

\author{
JOAN DAVID JANER TORRENS ${ }^{1}$ \\ Universidad de las Illes Balears \\ joandavidjaner@uib.es
}

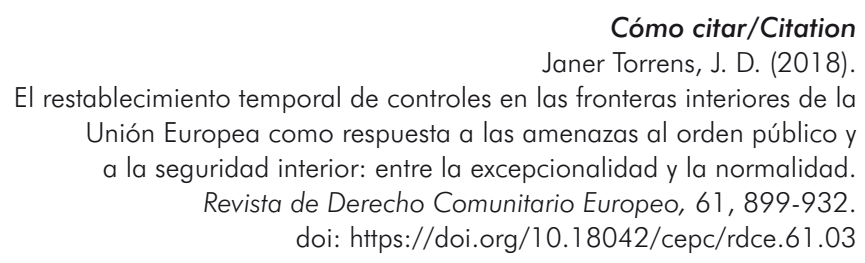

Resumen

En los últimos años, los controles fronterizos en el seno del espacio Schengen se han restablecido y prorrogado casi cincuenta veces como respuesta a los movimientos secundarios de migrantes irregulares y del aumento de las amenazas terroristas transfronterizas al considerarse que ambos elementos constituían amenazas al orden público y a la seguridad interior de los Estados. La imposición de controles parece, por tanto, que ha adquirido una cierta normalidad cuando precisamente la propia Comisión recuerda, de forma sistemática, que su aplicación debe ser excepcional y limitada en el tiempo. Este estudio pretende hacer una valoración del restablecimiento de los controles fronterizos a partir de lo previsto en la normativa en vigor y de la

1 Profesor titular de Derecho Internacional Público, Universidad de las Illes Balears. El presente estudio se ha realizado en el marco del proyecto DER 2015-65486-R subvencionado por el Ministerio de Economía y Competitividad. 
práctica existente con el objetivo de determinar su incidencia en la definición actual y futura del espacio Schengen como un ámbito que pretende realmente garantizar una libre circulación de personas.

\title{
Palabras clave
}

Libre circulación de personas; espacio Schengen; restablecimiento de controles en frontera; suspensión de la libre circulación de personas; orden público; seguridad interior.

\section{THE TEMPORARY RESTABLISHMENT OF BORDER CONTROLS WITHIN THE INTERNAL FRONTIERS OF THE EUROPEAN UNION AS A RESPONSE TO THREATS TO THE PUBLIC ORDER AND TO INTERNAL SECURITY: BETWEEN EXCEPTIONALITY AND NORMALITY}

\begin{abstract}
In recent years, border controls within the Schengen area have been restored and extended almost fifty times in response to the secondary movements of irregular migrants and the increase in cross-border terrorist threats as both elements were considered threats to public order and the internal security of the States. The imposition of controls seems, therefore, to have acquired a certain normality when precisely the Commission itself recalls, in a systematic way, that its application must be exceptional and limited in time. This study intends to make an assessment of the reestablishment of border controls based on the provisions of current legislation and existing practice in order to determine its impact on the current and future definition of the Schengen area as an area that really seeks to ensure free movement of persons.
\end{abstract}

\section{Keywords}

Free movement of persons; Schengen area; re-establishment of border controls; suspension of the free movement of persons; public order; internal security.

\section{LA RESTAURATION TEMPORAIRE DES CONTRÔLES SUR LES FRONTIÈRES INTERNES DE L'UNION EUROPÉENNE COMME RÉPONSE AUX MENACES À L'ORDRE PUBLIC ET À LA SÉCURITÉ INTÉRIEURE: ENTRE L'EXCEPTIONNALITÉ ET LA NORMALITÉ}

Résumé

Ces dernières années, les contrôles aux frontières dans l'espace Schengen ont été restaurés et étendus près de cinquante fois en réponse aux mouvements secondaires 
des migrants en situation irrégulière et une augmentation des menaces terroristes transfrontalières lorsque l'on considère les deux éléments constituaient des menaces à l'ordre public et la sécurité intérieure des États. L'imposition de contrôles semble donc avoir acquis une certaine normalité lorsque la Commission elle-même rappelle, de manière systématique, que son application doit être exceptionnelle et limitée dans le temps. Cette étude vise à faire une évaluation de la réintroduction des contrôles aux frontières à la lumière des dispositions de la législation en vigueur et des pratiques existantes afin de déterminer son impact sur la définition actuelle et future de l'espace Schengen comme un domaine qui vise vraiment à rendre efficace la libre circulation des personnes.

\section{Mots clés}

Libre circulation des personnes; espace Schengen; restauration des contrôles aux frontières; suspension de la libre circulation des personnes; ordre public; sécurité intérieure. 


\section{SUMARIO}

I. INTRODUCCIÓN. II. LA CONFIGURACIÓN INICIAL DE LA CLÁUSULA DE SUSPENSIÓN. III. EL RESTABLECIMIENTO DE LOS CONTROLES FRONTERIZOS EN SUPUESTOS PREVISIBLES O URGENTES PREVISTO EN EL REGLAMENTO 562/2006. IV. LA NUEVA REGULACIÓN DE LOS SUPUESTOS DE RESTABLECIMIENTO DE LOS CONTROLES FRONTERIZOS PREVISTA EN EL REGLAMENTO 1051/2013: 1. Marco general sobre el restablecimiento de fronteras en casos previsibles. 2. El restablecimiento de fronteras en casos que exijan una respuesta inmediata. 3. El restablecimiento de fronteras en caso de circunstancias excepcionales que pongan en peligro el funcionamiento general del espacio sin fronteras interiores. V. LA IMPORTANCIA CRECIENTE DEL RESTABLECIMIENTO DE LOS CONTROLES FRONTERIZOS EN CASO DE DEFICIENCIAS GRAVES Y PERSISTENTES EN LOS CONTROLES DE LAS FRONTERAS EXTERIORES. VI. LA ACTUALIZACIÓN DE LA REGULACIÓN RELATIVA AL RESTABLECIMIENTO DE LOS CONTROLES FRONTERIZOS: EL REFORZAMIENTO DE LOS CONTROLES POLICIALES Y LA PROLONGACIÓN DE LOS PLAZOS: 1. Los controles policiales y la cooperación policial como vías alternativas al restablecimiento de los controles fronterizos. 2. La prolongación de los plazos del restablecimiento temporal de los controles fronterizos. VII. EL CONTROL JUDICIAL INTERNO DE LA DECISIÓN DE PRORROGAR LOS CONTROLES FRONTERIZOS: LA SENTENCIA DE 28 DE DICIEMBRE DE 2017 DEL CONSEJO DE ESTADO FRANCÉS. VIII CONSIDERACIONES FINALES. BIBLIOGRAFíA.

\section{INTRODUCCIÓN}

La libre circulación de personas entre los veintiséis Estados miembros del espacio Schengen se ha visto afectada de forma muy negativa, especialmente a partir de 2015, como consecuencia de los movimientos secundarios (desplazamiento entre países) de migrantes irregulares y del aumento de las amenazas terroristas transfronterizas. Determinados Estados, alegando que estos elementos incidían en su seguridad interior y tenían un claro impacto en la preservación de su orden público, han restablecido de forma temporal los controles en sus fronteras para hacer frente a dichas amenazas. La Comisión Europea ha señalado que, en los últimos dos años (entre octubre de 2015 y octubre de 2017), se han restablecido y prorrogado casi cincuenta veces los controles fronterizos en el espacio Schengen, mientras que en el periodo 2006-2015 se 
plantearon 36 casos de restablecimiento de fronteras ${ }^{2}$. Al margen del impacto económico que pueden tener las decisiones adoptadas de forma unilateral por los Estados 3 , estas también inciden en la propia definición y consistencia del espacio Schengen en la medida en que el restablecimiento y prórrogas posteriores de los controles fronterizos parece que ha ido adquiriendo últimamente una normalidad que desvirtúa su carácter excepcional.

El Convenio de Aplicación del Acuerdo de Schengen de 1990 preveía, en su art. 2, la denominada "cláusula de suspensión», cuyo contenido estaba poco elaborado y que permitía el restablecimiento temporal de los controles fronterizos por motivos de orden público o seguridad nacional. De forma progresiva, distintos Estados invocaron dicha cláusula, lo cual planteó la necesidad de precisar más sus contornos dada su excepcionalidad. La aprobación en 2006 del Código de Fronteras Schengen supuso, a la par que se producía un aumento importante de la invocación de la cláusula de suspensión, un avance en este ámbito al establecerse distintos procedimientos relativos al restablecimiento temporal de los controles en las fronteras interiores. En los últimos años, como consecuencia de la fuerte presión sobre las fronteras exteriores e interiores derivada de los flujos migratorios y de los distintos atentados terroristas que se han producido, numerosos Estados han invocado y aplicado la cláusula de suspensión. Progresivamente, su contenido se ha ido modelando a través de las distintas reformas del Código de Fronteras Schengen, de las disposiciones relativas a la Guardia Europea de Fronteras y Costas, las relativas a los controles policiales y a la cooperación policial, así como por la jurisprudencia sobre los controles fronterizos encubiertos elaborada por el TJUE.

La imposición de controles parece, por tanto, que ha adquirido una cierta normalidad cuando precisamente la propia Comisión recuerda, de forma sistemática, que su aplicación debe ser excepcional y limitada en el tiempo.

2 Exposición de motivos de la propuesta de reglamento que modifica el Reglamento $2016 / 399$ en lo que respecta a las normas aplicables al restablecimiento temporal de controles fronterizos en las fronteras interiores [COM (2017) 571 final, de 27 de septiembre de 2017, p. 2].

3 La Comisión ha señalado que las retenciones en la frontera tendrían considerables repercusiones sobre el transporte transfronterizo (especialmente por carretera), el turismo, las administraciones públicas y los trabajadores y viajeros transfronterizos con unos costes directos que oscilarían entre 5000 y 18000 millones de euros al año (es decir, entre 0’06 \% y 0’13\% del PIB (Comunicación de la Comisión sobre la protección y el refuerzo de Schengen [COM (2017) 570 final, de 27 de septiembre de 2017 , p. 3]. Junto a esta dimensión económica, el restablecimiento de los controles fronterizos también tiene consecuencias para las regiones fronterizas. En relación con esta cuestión, véase Evard et al. (2018). 
Este estudio pretende hacer una valoración de la cláusula de suspensión a partir de lo previsto en la normativa en vigor y de la práctica existente con el objetivo de determinar su incidencia en la definición actual y futura del espacio Schengen como un ámbito que pretende realmente garantizar una libre circulación de personas.

\section{LA CONFIGURACIÓN INICIAL DE LA CLÁUSULA DE SUSPENSIÓN}

Después de afirmarse en el art. 2, apdo. primero, del Convenio de Aplicación del Acuerdo de Schengen de 1990 que las fronteras interiores de los países miembros de Schengen podían cruzarse sin control alguno sobre las personas, el apdo. segundo configuró por primera vez el contenido de la cláusula de suspensión de la libre circulación de personas con un contenido doble $e^{4}$ Por una parte, los Estados podían, previa consulta con los demás Estados, invocar razones de orden público o de seguridad nacional (también se utiliza el término "seguridad pública» o "seguridad interna») para imponer por un periodo limitado de tiempo controles en las fronteras 5 . Por otra parte, si fuese preciso adoptar dichas medidas de forma inmediata, se permitía su adopción con la posterior información al resto de partes contratantes.

La entrada en vigor del Convenio de Aplicación del Acuerdo de Schengen se produjo el 26 de marzo de 1995 y, el 20 de diciembre, el Comité Ejecutivo —órgano encargado de aplicar el convenio- aprobó una decisión

4 Si bien, quizás por influencia del francés o del inglés, en algún documento oficial se alude al término "cláusula derogatoria», se ha optado en este estudio por utilizar el término «cláusula de suspensión», pues nos encontramos ante una suspensión (que no derogación) temporal de la libre circulación de personas con el objetivo de salvaguardar el orden público y la seguridad interna.

5 ElTJUE ha aludido en su jurisprudencia a los conceptos de «orden público» $\mathrm{y}$ «seguridad interior", especialmente en casos relativos a la aplicación de la Directiva 2004/38 relativa al derecho de circulación y residencia de los ciudadanos de la Unión y de sus familiares, y ha afirmado, en relación con el orden público, que este requiere «[...] aparte de la perturbación del orden social que constituye cualquier infracción de ley, que exista una amenaza real, actual y suficientemente grave que afecte a un interés fundamental», mientras que la seguridad interior "[... puede verse afectada, en particular, por una amenaza directa para la tranquilidad y seguridad física de la población del Estado miembro de que se trate» (Sentencia del Tribunal de Justicia de 2 de mayo de 2018, K. y H. F., C-331/16 y C-366/16, EU:C:2018:296, apdos. 41 y 42. En este mismo sentido, Sentencia del Tribunal de Justicia de 24 de junio de 2015, H. T., C-373/13, EU:C:2015, apdo. 79). Véase, asimismo, Martín Martínez (2014). 
relativa a la aplicación de la cláusula de suspensión prevista en el art. 2 señala$\mathrm{do}^{6}$. Así, se daba forma y contenido al procedimiento en caso de consulta previa (el Estado interesado en el restablecimiento temporal debía notificar al resto de Estados las causas, el alcance y duración de la decisión y precisar qué medidas esperaba que adoptasen algunos o todos los Estados para evitar el restablecimiento de los controles e iniciar una fase de consulta que podía desembocar en el establecimiento temporal y limitado de controles fronterizos) y al procedimiento en caso de decisión inmediata (el Estado interesado podía imponer controles sin necesidad de iniciar un plazo de consultas pero también debía exponer al resto de Estados las causas, alcance y duración de la suspensión de la libre circulación de personas). La decisión del Comité Ejecutivo también instaba al Estado afectado a concretar la fecha de supresión de los controles y también preveía la posibilidad de prorrogar los controles siempre de forma justificada.

Durante los primeros años de vigencia del Convenio de Aplicación del Acuerdo de Schengen, se produjo una aplicación más bien limitada de la cláusula de suspensión ${ }^{7}$. Cabe destacar que dicha aplicación se llevó a cabo al margen de lo previsto en el art. 2 del Convenio y de la «Decisión de desarrollo» adoptada por el Comité Ejecutivo. No hubo consultas previas ni se facilitó con posterioridad información al resto de Estados parte. Sencillamente, el Estado que optaba por restablecer los controles fronterizos enviaba una carta a la Secretaría General del Consejo notificando su decisión unilateral ${ }^{8}$.

\section{EL RESTABLECIMIENTO DE LOS CONTROLES FRONTERIZOS EN SUPUESTOS PREVISIBLES O URGENTES PREVISTO EN EL REGLAMENTO 562/2006}

Con la entrada en vigor, el 13 de octubre de 2006, del Reglamento 562/2006, de 15 de marzo de 2006', que creó el Código de Fronteras Schen-

6 SCH/Com-ex (95) 20, 2a rev. (DO L 239, de 22 de septiembre de 2000).

7 Groenendijk (2004: 158); Statewatch European Monitor, Vol. 3, n.o 4, 2003.

8 Olesti Rayo ha observado que uno de los problemas de la aplicación de la cláusula de suspensión hacía referencia a la falta de transparencia de los Estados a la hora de restablecer los controles fronterizos. El problema se ligaba a la falta de un registro oficial que recogiese todas las ocasiones en que los Estados miembro restablecían los controles y las causas que los habían motivado. Ello se solucionó en 2006 a través de la elaboración de informes al respecto por parte de la Comisión (Olesti Rayo, 2012: 72).

$9 \quad$ DO L 105, de 13 de abril de 2006. 
gen, se produjo la derogación del art. 2 del Convenio de Aplicación del Acuerdo de Schengen y de la «Decisión de desarrollo». La creación de un nuevo régimen relativo al control en las fronteras exteriores y de medidas comunes en materia de cruce de personas por las fronteras interiores de los Estados integrantes del espacio Schengen implicó una nueva regulación de las condiciones y procedimientos relativos al restablecimiento de los controles fronterizos que se debían guiar por su excepcionalidad y por el respeto del principio de proporcionalidad. Así, el nuevo Código de Fronteras Schengen dedicaba una regulación específica al restablecimiento temporal de los controles en las fronteras interiores dependiendo de que se tratase de supuestos previsibles o urgentes. En el primer supuesto, el art. 23 señalaba que un Estado podía, de forma excepcional y por el mínimo plazo de tiempo necesario que, en principio, no podía superar los treinta días (si bien se podía ampliar si se justificaba), invocar una amenaza grave para su orden público o su seguridad interior para restablecer los controles en sus fronteras y se establecía el procedimiento a seguir, en el cual se preveía la existencia de unas consultas previas con el resto de Estados con una antelación de quince días antes del restablecimiento de los controles fronterizos ${ }^{10}$. El segundo supuesto previsto en el artículo 25 permitía a un Estado, siguiendo también un procedimiento y una exposición y justificación de los motivos, la imposición inmediata, y sin necesidad de señalar el periodo de vigencia, de controles fronterizos cuando el orden público o la seguridad interior exigiesen una actuación urgente. En todo caso, el artículo 26 del Reglamento 562/2006 fijaba un procedimiento que permitía (previa comunicación de la información justificativa al resto de Estados y a la Comisión) la prolongación de los controles en las fronteras interiores.

Ciertamente, la nueva redacción de la cláusula de suspensión con la previsión de dos supuestos y del procedimiento para su aplicación supuso un avance respecto de la anterior regulación. El restablecimiento de controles fronterizos era una prerrogativa de cada Estado a la cual ni el resto de Estados ni la Comisión (si bien podía emitir un dictamen) se podía oponer.

En 2010, a partir de la exigencia prevista en el art. 38 del Código de Fronteras Schengen, la Comisión publicó un informe en el que se recogían por primera vez de forma oficial los distintos supuestos de aplicación de la

10 Así, el art. 24 aludía a la necesidad de comunicar lo antes posible la decisión al resto de Estados y a la Comisión (que podía emitir un dictamen al respecto) la siguiente información: motivos que se alegaban y su incidencia en el orden público o la seguridad interior, alcance y puntos en los que se restablecerían las fronteras, denominación de los pasos fronterizos habilitados, fecha y duración del restablecimiento previsto y, en su caso, medidas que debían adoptar los demás Estados miembros. 
cláusula de suspensión que se habían producido entre la entrada en vigor del Código y junio de $2010^{11}$. En este periodo, doce Estados del espacio Schengen habían restablecido los controles fronterizos en veintidós ocasiones con el objetivo de permitir a las autoridades policiales gestionar las medidas de seguridad necesarias en el marco de acontecimiento deportivos, manifestaciones políticas o reuniones políticas de alto nivel ${ }^{12}$. Una de las críticas que hacía la Comisión a los Estados era que la información facilitada por estos para hacer posible el restablecimiento temporal de los controles en las fronteras interiores era "[...] muy general y no permite evaluar totalmente la efectividad de las medidas adoptadas con respecto a la amenaza para el orden público y la seguridad interior" ${ }^{\prime 3}$. Además, en la práctica, no se seguía el procedimiento fijado en caso de supuestos previsibles puesto que los Estados no solo no facilitaban la información exigida en el art. 24 del Reglamento 562/2006, sino que el plazo entre la notificación de la decisión de imponer controles fronterizos y su restablecimiento de facto era tan breve que imposibilitaba a la Comisión emitir el correspondiente dictamen al respecto y, por ello, en ninguno de los veintidós supuestos hubo un dictamen previo de la Comisión.

\section{LA NUEVA REGULACIÓN DE LOS SUPUESTOS DE RESTABLECIMIENTO DE LOS CONTROLES FRONTERIZOS PREVISTA EN EL REGLAMENTO 1051/2013}

La gestión de los flujos de inmigrantes y la fuerte presión que estos ejercían sobre las fronteras interiores ${ }^{14} \mathrm{y}$ exteriores de la Unión con motivo de la

11 Informe de la Comisión sobre la aplicación del título III (Fronteras interiores) del Reglamento 562/2006 por el que se establece un Código comunitario de normas para el cruce personas por las fronteras (Código de fronteras Schengen) [COM (2010) 554 final, de 13 de octubre de 2010].

12 Así, en catorce ocasiones se restablecieron los controles fronterizos con motivo de reuniones o cumbres internacionales como reuniones del G8, de la OTAN, de los jefes de Estado y de Gobierno de la Unión, de la celebración de cumbres UE-África, reuniones de los ministros de la OSCE, de una visita papal, de la celebración de conferencias internacionales o de la concesión del Premio Nobel. En tres ocasiones el restablecimiento respondió a la celebración de competiciones deportivas y en cinco ocasiones a manifestaciones de personas simpatizantes con el grupo terrorista ETA y el movimiento abertzale (Ibid., p. 13-15).

13 Ibid., p. 9.

14 En los primeros meses de 2011 hubo dos supuestos importantes de restablecimiento de los controles fronterizos. Por una parte, en abril de 2011, Francia impuso controles 
desestabilización de la situación política en sus países de origen, derivada de las llamadas «primaveras árabes», hizo que la Comisión se plantease en 2011 la necesidad de adoptar un mecanismo que permitiese a la Unión afrontar aquellas situaciones derivadas de la falta de diligencia de determinados Estados en controlar su frontera exterior o de la imposibilidad de hacerlo debido a fuertes presiones inesperadas (como la llegada masiva de inmigrantes) ${ }^{15}$. Se pretendía superar el planteamiento unilateral vigente hasta el momento en relación con la imposición de controles fronterizos mediante el diseño de un mecanismo que permitiese a la Unión dar una respuesta coordinada en situaciones críticas, lo cual aumentaría la confianza entre los Estados miembros y reduciría el recurso a iniciativas unilaterales. De esta manera, se decidiría a nivel europeo qué Estados podrían volver a introducir de forma excepcional los controles en las fronteras interiores y por cuanto tiempo ${ }^{16}$.

Sobre la base de la propuesta presentada por la Comisión ${ }^{17}$, se adoptó el Reglamento $1051 / 2013^{18}$, el cual derogaba el régimen de restablecimiento temporal de los controles fronterizos vigente desde 2006 con la entrada en vigor del Código de Fronteras Schengen y preveía unos procedimientos más elaborados de suspensión que se guiaban por su carácter excepcional y proporcional y por otorgar un papel más relevante a la Comisión en el control del procedimiento de restablecimiento temporal de fronteras ${ }^{19}$. El Reglamento

en su frontera con Italia con el objetivo de evitar la entrada en su territorio de inmigrantes procedentes del norte de África a quienes Italia había concedido permisos de residencia temporales, mientras que, en mayo de ese mismo año, por cuestiones de política interna, Dinamarca reforzó e intensificó los controles en sus fronteras con Alemania y Suecia. En relación con ambos supuestos, véase, respectivamente, Carrera et al., (2011); Jorgensen y Sorensen (2012: 250).

15 Comunicación de la Comisión sobre migración [COM (2011) 248 final, de 4 de mayo de 2011, p. 8].

16 El Consejo Europeo, en su reunión de los días 23 y 24 de junio de 2011, acogió favorablemente la idea expuesta por la Comisión al señalar que «[...] como último recurso, se podría establecer dentro de ese mecanismo una cláusula de salvaguardia que autorizara el restablecimiento excepcional de los controles fronterizos internos, en una situación auténticamente grave en la que un Estado miembro ya no pudiera cumplir las obligaciones impuestas por las normas de Schengen» (párr. 22 de las conclusiones, EUCO 23/1/11 REV 1, p. 8).

17 COM (2011) 560 final, de 16 de septiembre de 2011.

18 DO L 295, de 6 de noviembre de 2013.

19 Teniendo en cuenta que la libre circulación de personas sin controles era una de las principales realizaciones de la UE, la Comisión consideraba que era necesaria una respuesta a nivel de la Unión cuando dicha libertad pudiese verse afectada por una 
1051/2013 buscaba reforzar la gestión del espacio Schengen otorgando un papel más relevante a la Comisión, al Consejo y al Parlamento en la medida en que, sobre la base de unos criterios acordados en común, serían estas instituciones las que, salvo supuestos excepcionales en los cuales los Estados podían continuar decidiendo la suspensión unilateral de la libre circulación de personas, supervisarían la imposición temporal de controles fronterizos.

Antes de entrar en el análisis de la nueva regulación de la cláusula de suspensión, cabe destacar que, en la exposición de motivos del Reglamento $1501 / 2013$, se señala que el restablecimiento de los controles fronterizos por motivos de orden público o seguridad interior se vincula con «los actos o amenazas terroristas o de riesgos relacionados con la delincuencia organizada», pero no con los problemas derivados de la llegada de inmigrantes en situación irregular en la medida en que «la migración y el cruce de las fronteras exteriores por un gran número de nacionales de terceros países no deben considerarse por sí mismos una amenaza para el orden público o la seguridad interior ${ }^{20}$.

Con la entrada en vigor del Reglamento 1501/2013 se preveían tres supuestos (dos de ellos ya estaban previstos en ese momento) de restablecimiento de los controles fronterizos: a) el relativo al marco general del restablecimiento de fronteras (arts. 23 a 24); b) el relativo a casos que requieran una actuación inmediata (art. 25); y c) el relativo a la existencia de circunstancias excepcionales que pongan en riesgo el funcionamiento general del espacio sin fronteras interiores (arts. 26 y 26 bis).

decisión nacional unilateral y, a veces, opaca. Por ello entendía necesario «[...] velar por que la reintroducción excepcional y temporal de los controles en las fronteras interiores se decida de acuerdo con el método comunitario y tomar en consideración la responsabilidad política general de la Comisión ante el Parlamento Europeo» (Comunicación de la Comisión relativa a la Gobernanza de Schengen - Refuerzo del espacio sin controles fronterizos en las fronteras interiores - [COM (2011) 561 final, de 16 de septiembre de 2011, p. 3].

20 A pesar de esta afirmación, los distintos supuestos de restablecimiento de controles fronterizos que se han producido se han vinculado esencialmente a la afluencia masiva de personas en busca de protección internacional y, por tanto, los Estados han considerado que hay una vinculación entre los movimientos secundarios de inmigrantes irregulares y el mantenimiento del orden público y la seguridad interior. La propia Comisión ha señalado que ello, a pesar de lo dispuesto en el considerando del reglamento «[...] sí supone en la práctica una amenaza para el orden público y la seguridad interior»; Dictamen de la Comisión de 23 de octubre de 2015 sobre la necesidad y proporcionalidad de los controles en las fronteras interiores restablecidos por Alemania y Austria [C (2015) 7100 final, p. 8]. 


\section{MARCO GENERAL SOBRE EL RESTABLECIMIENTO DE FRONTERAS EN CASOS PREVISIBLES}

En relación con el marco general de la regulación del restablecimiento de fronteras en supuestos previsibles en caso de amenaza grave para el orden público y la seguridad interior se establecía básicamente el mismo régimen y procedimiento que el vigente desde 2006 con el Código de Fronteras Schengen: suspensión de la libre circulación de personas por un periodo de tiempo limitado no superior a treinta días o el tiempo mínimo necesario en caso de sobrepasarse dicho plazo ${ }^{21}$. En caso de que la amenaza para el orden público y la seguridad interior persistiese, se permitía prolongar los controles fronterizos durante periodos renovables que no sobrepasasen treinta días hasta un máximo de seis meses. Ahora bien, en caso de que se constatase la concurrencia de circunstancias excepcionales que pusiesen en riesgo el funcionamiento general del espacio sin controles en las fronteras interiores como consecuencia de deficiencias graves persistentes en las fronteras exteriores (supuesto no previsto hasta el momento), el periodo total de suspensión de la libre circulación de personas se podía alargar hasta los dos años. El Reglamento 1051/2013, en su art. 23 bis, introdujo la novedad de que los Estados debían evaluar si el restablecimiento de los controles fronterizos podía responder correctamente a la amenaza al orden público y a la seguridad interior y si ello era proporcional en relación con la amenaza a la que se quería hacer frente $y$, por ello, se debían tener en cuenta las repercusiones de dicha decisión para el orden público o la seguridad interior y para la libre circulación de personas.

En el procedimiento que se diseñaba para activar la cláusula de suspensión en caso de supuestos previsibles, a diferencia del vigente hasta el

21 Según la Comisión entrarían en este supuesto la celebración de grandes acontecimientos deportivos, de manifestaciones de carácter político o reuniones políticas de alto nivel (Comunicación sobre la Gobernanza de Schengen, cit. supra, p. 12). Como ejemplo de este supuesto, cabe aludir al restablecimiento de los controles fronterizos por Malta entre el 21 de enero y el 9 de febrero de 2017 con motivo de una reunión informal de los jefes de Estado y de Gobierno de la Unión; a la suspensión de la libre circulación de personas por Polonia entre el 4 de julio y el 2 de agosto de 2016 con motivo de una cumbre de jefes de Estado y de Gobierno de la OTAN y de la visita del Papa; o al restablecimiento por Francia de los controles en todas sus fronteras entre el 27 de mayo y el 26 de julio de 2016 con motivo del Tour de Francia y de la celebración del campeonato europeo de fútbol (Temporary Reintroduction of border control, Migration and Home Affairs, European Commission. Informe disponible en: https:// bit.ly/2kFAQ84). 
momento en que no se fijaba un plazo, se señalaba, en el art. 24, que el restablecimiento de controles se debía notificar al menos con cuatro semanas de antelación al resto de Estados, a la Comisión, al Parlamento Europeo y al Consejo y se debían hacer constar los motivos, alcance de la suspensión, fecha y duración de la suspensión y pasos fronterizos afectados. Si, a partir de la información facilitada, surgiesen dudas respecto de la necesidad o proporcionalidad de la decisión comunicada por el Estado, la Comisión o cualquier Estado podían emitir un dictamen a partir del cual se llevarían a cabo diferentes reuniones (fijándose un mínimo de diez días de antelación a la fecha prevista para activar la cláusula de suspensión) entre todas las partes (Estado que tomaba la decisión, resto de Estados y Comisión) con el objeto de promover la cooperación entre los Estados y examinar la proporcionalidad de las medidas previstas.

\section{EL RESTABLECIMIENTO DE FRONTERAS EN CASOS QUE EXIJAN UNA RESPUESTA INMEDIATA}

En el supuesto de concurrencia de amenazas al orden público y a la seguridad interior que exigiesen una respuesta inmediata ${ }^{22}$, el art. 25 permitía

22 Según la Comisión Europea, entrarían en este supuesto «[...] atentados terroristas u otros actos delictivos de gran envergadura», los cuales exigen "[...] la adopción de todas las medidas posibles para garantizar la detención rápida de los autores de los actos de que se trate» (Ibid.). En este mismo documento, la Comisión señalaba que «el paso de la frontera exterior por un gran número de nacionales de terceros países puede, en algunas circunstancias, justificar la reintroducción inmediata de algunos controles en las fronteras interiores durante un periodo determinado». Sobre la base de este art. 25, entre septiembre de 2015 y junio de 2016, Bélgica, Dinamarca, Alemania, Hungría, Eslovenia, Suecia y Noruega notificaron su decisión de restablecer los controles fronterizos al entender que la afluencia masiva de personas indocumentadas o mal documentadas, incluso menores, que no fueron registradas en el momento de su primera entrada en la UE, así como el hecho de que estos movimientos masivos llevaban al límite las capacidades de acogida, exigía una respuesta inmediata. Si bien la mayoría de supuestos de restablecimiento de las fronteras de forma inmediata se ha vinculado a la gestión de los flujos migratorios, también se ha invocado este artículo como respuesta de los Estados en caso de atentados terroristas. Francia ha sido el país que durante más tiempo ha restablecido los controles fronterizos por este motivo. Los atentados terroristas de Niza y París y el nivel de alerta decretado han supuesto que, prácticamente, desde diciembre de 2015 hasta abril de 2018, ha habido controles en todas las fronteras de Francia. En 2011 y 2014, Noruega suspendió puntualmente (días y como máximo una semana) la libre circulación de personas como respuesta a 
que, de forma excepcional, un Estado pudiera restablecer los controles fronterizos por un periodo no superior a diez días con la posibilidad de prolongarlo durante veinte días y, en casos excepcionales, un máximo de dos meses. En la regulación anterior se aludía a la necesidad de llevar a cabo actuaciones urgentes (frente a la nueva inmediatez) y no se fijaba un plazo de vigencia. Se mantenía, en todo caso, el deber de facilitar a la Comisión y al resto de Estados toda la información con los motivos, alcance de la suspensión, fecha y duración de la suspensión y pasos fronterizos afectados, los cuales podrían emitir un dictamen al respecto ${ }^{23}$. La Comisión debía informar al Parlamento Europeo de las notificaciones existentes relativas a supuestos de actuación inmediata.

\section{EL RESTABLECIMIENTO DE FRONTERAS EN CASO DE CIRCUNSTANCIAS EXCEPCIONALES QUE PONGAN EN RIESGO EL FUNCIONAMIENTO GENERAL DEL ESPACIO SIN FRONTERAS INTERIORES}

El Reglamento 1051/2013 introducía en el art. 26 un nuevo supuesto de restablecimiento de controles fronterizos no previsto hasta el momento: la existencia de circunstancias excepcionales que impliquen una amenaza grave para el orden público o para la seguridad interior y que pongan en riesgo el funcionamiento general del espacio sin fronteras interiores como consecuencia de deficiencias graves persistentes en los controles de las fronteras exteriores ${ }^{24}$.

las amenazas terroristas, y también lo hizo Suecia durante un día a raíz de la matanza en la isla noruega de Utoya en julio de 2011 (Ibid., p. 5).

23 En el dictamen de la Comisión de 23 de octubre de 2015 sobre la necesidad y proporcionalidad de los controles en las fronteras interiores restablecidos por Alemania y Austria [C (2015) 7100 final], se puso de manifiesto la conformidad con el Código de Fronteras Schengen de la imposición temporal (y prórrogas posteriores) de controles fronterizos por parte de Alemania y Austria sobre la base de que los extraordinarios flujos de personas en el territorio de estos dos países exigía el restablecimiento inmediato de los controles en las fronteras. El restablecimiento temporal tenía por objeto «[...] prestar una ayuda adecuada a las personas que llegaban mediante, entre otras, procedimientos más estructurados, especialmente en términos de registro", lo cual permitía también controlar la entrada de personas vinculadas a la delincuencia o miembros de grupos militantes extremistas o extremistas que actuaban en solitario.

24 La fuerte presión migratoria que, en la primera década del siglo xxI, padecieron determinados países que eran frontera exterior de la Unión, como Grecia, Italia o Malta, y la incapacidad, por la magnitud de los flujos, de controlar de forma efectiva dichas fronteras hizo que otros países del espacio Schengen desconfiaran de la capacidad de 
Este nuevo supuesto se basaba en la constatación de deficiencias importantes en la gestión de las fronteras exteriores por parte de un Estado a partir de los informes de evaluación del acervo Schengen elaborados conforme al nuevo Reglamento 1053/201325. Conforme al nuevo art. 19 bis introducido por el Reglamento 1051/2013, era necesario que previamente se hubiese constatado el fracaso de las recomendaciones previstas en un acto de ejecución adoptado por la Comisión dirigido al Estado al que se consideraba que presentaba graves deficiencias en el control de sus fronteras exteriores.

Ante la constatación de la falta de diligencia de un Estado en el control de sus fronteras exteriores, se permitía, a partir de la existencia de una recomendación del Consejo a propuesta de la Comisión ${ }^{26}$, que uno o más Estados suspendiesen la libre circulación de personas en todas sus fronteras interiores o en parte de ellas por un periodo de seis meses, prorrogables tres veces hasta un máximo de veinticuatro meses (por tanto, un máximo de dos años). En todo caso, era el Consejo quien, a través de su recomendación, permitía el restablecimiento temporal de los controles en las fronteras interiores para hacer frente a las deficiencias detectadas.

aquellos para gestionar de forma correcta las fronteras con los perjuicios (movimientos secundarios de inmigrantes irregulares por todo el espacio Schengen) que ello implicaba para el resto de países. En la ya citada comunicación de 2011 sobre migración, la Comisión propuso por primera vez incorporar el nuevo supuesto de restablecimiento de los controles fronterizos en caso de deficiencias en los controles en las fronteras exteriores. En este sentido, señaló que «[...] hay que establecer un mecanismo que permita a la Unión afrontar aquellas situaciones en las que, bien un Estado miembro no cumple su obligación de controlar su sección de la frontera exterior, bien una parte específica de la frontera exterior se ve sometida a fuertes presiones inesperadas debidas a acontecimientos externos» (p. 8).

25 Reglamento 1053/2013 del Consejo, de 7 de octubre de 2013, por el que se establece un mecanismo de evaluación y seguimiento para verificar la aplicación del acervo de Schengen (DO L 295, de 6 de noviembre de 2013).

26 La recomendación de restablecer los controles fronterizos debía hacerse después de evaluar aspectos como la disponibilidad de medidas de apoyo técnico y financiero prestadas por la Oficina Europea de Apoyo al Asilo o por Europol, las repercusiones actuales o futuras derivadas de la existencia de deficiencias graves en los controles en las fronteras exteriores y las consecuencias que implicaban para la libre circulación de personas el restablecimiento de controles fronterizos. Cabe entender que esta recomendación es un requisito legal para que un Estado imponga controles fronterizos de tal manera que si estos se adoptan sin que exista una recomendación del Consejo sería posible iniciar, conforme al art. 258 del TFUE, un procedimiento por infracción por parte de la Comisión. 
En los tres supuestos de restablecimiento de controles en las fronteras interiores se establecía que el Estado que hubiese suspendido la libre circulación de personas debía, en un plazo máximo de cuatro semanas, presentar un informe a la Comisión, al Consejo y al Parlamento Europeo aludiendo al cumplimiento del procedimiento fijado al efecto, a su funcionamiento, a los efectos sobre la libre circulación de personas, a su eficacia y a si el restablecimiento había sido proporcional a las amenazas detectadas. De esta manera, se reforzaba la idea de que la aplicación de la cláusula de suspensión constituía el último recurso al que acudir por su excepcionalidad y que los Estados debían justificar y seguir un procedimiento fijado con una importante participación de las instituciones, especialmente de la Comisión ${ }^{27}$.

\section{LA IMPORTANCIA CRECIENTE DEL RESTABLECIMIENTO DE LOS CONTROLES FRONTERIZOS EN CASO DE DEFICIENCIAS GRAVES Y PERSISTENTES EN LOS CONTROLES DE LAS FRONTERAS EXTERIORES}

A raíz del fuerte incremento en 2015 de los flujos migratorios hacia determinados países de la Unión (en 2015, más de 868000 personas entraron de forma irregular en el espacio Schengen a través de Grecia ${ }^{28}$, un año más tarde se adoptó y entró en vigor el Reglamento 2016/39929 que contiene la regulación actual del Código de Fronteras Schengen y en el cual se mantenían en los mismos términos los dos supuestos generales de restablecimiento de fronteras (en casos previsibles y en casos que exigiesen una respuesta inmedia-

27 Peers (2013: 32) observó que la nueva regulación de la cláusula de suspensión representaba un compromiso entre la voluntad de los Estados de restablecer de forma unilateral los controles fronterizos en caso de amenaza para su orden público y seguridad interior y la voluntad de la Comisión de controlar todo el proceso aplicación de dicha cláusula debido a sus consecuencias negativas para la libre circulación de personas.

28 En relación con la gestión de los flujos migratorios, Olesti Rayo ha observado que "[...] desde su creación [refiriéndose al espacio Schengen] se han planteado problemas respecto de la capacidad de algunos países para gestionar los flujos migratorios y se ha hecho patente la desconfianza respecto al control eficiente de las fronteras exteriores por determinados Estados miembros [...]. De todas formas, la dimensión del movimiento de personas es incomparable con cualquier situación anterior y no resiste analogía alguna» (2016: 244).

29 Reglamento 2016/399, de 9 de marzo de 2016, por el que se establece un Código de normas de la Unión para el cruce de personas por las fronteras (Código de fronteras Schengen) (DO L 77, de 23 de marzo de 2016). 
ta) y el específico vinculado a la existencia de deficiencias graves y persistentes en los controles de las fronteras exteriores. Pero la fuerte presión migratoria que padecían determinadas fronteras exteriores de la Unión (especialmente las de Grecia) y la constatación de que determinados Estados eran incapaces $^{30}$ de controlar sus fronteras hizo que, a través del Reglamento 2016/1624 que regulaba la nueva Guardia Europea de Fronteras y Costas (conocida comúnmente como FRONTEX) $)^{31}$, se modificase puntualmente el supuesto de suspensión de la libre circulación de personas en casos de deficiencias graves y persistentes previsto en el Código de Fronteras Schengen con el objetivo de hacer frente a los problemas existentes en el control de las fronteras exteriores y el consiguiente peligro que ello implicaba para el funcionamiento del espacio Schengen.

La nueva regulación del art. 29.1 relativa al procedimiento específico en circunstancias excepcionales que pongan en riesgo el funcionamiento general del espacio sin controles en las fronteras interiores del actual Código de Fronteras Schengen, introducida por el Reglamento 2016/1624, pretendía hacer frente a casos que se habían presentado en la práctica y que hacían referencia a los supuestos en que un Estado (como Grecia) no hubiese tomado las medidas necesarias para corregir los aspectos problemáticos en el control de fronteras constatados por FRONTEX en una evaluación previa de vulnerabilidad ${ }^{32} \mathrm{o}$ porque el Estado en cuestión no había solicitado ayuda a la Agencia Europea

30 La Comisión observó que Grecia no vigilaba de forma adecuada sus fronteras y que el registro e identificación de los migrantes irregulares era claramente insuficiente. Además, Grecia practicaba lo que la Comisión denominó una política de «permitir el paso» hacia otros países a los inmigrantes que llegaban a su territorio, lo cual suponía un incumplimiento de la normativa vigente en materia de asilo y refugio [Comunicación de la Comisión. Restablecer Schengen - Hoja de ruta - COM (2016) 120 final, de 4 de marzo de 2016, p. 12].

31 Reglamento 2016/1624, de 14 de septiembre de 2016, sobre la Guardia Europea de Fronteras y Costas (DO L 251, de 16 de septiembre de 2016). Los orígenes de esta guardia se remontan a la creación en 2004 de la Agencia Europea para la gestión de la cooperación operativa en las fronteras exteriores de los Estados miembros de la Unión Europea creada mediante el Reglamento 2007/2004, de 26 de octubre (DO L 349, de 25 de noviembre de 2004). En relación con esta cuestión, véase Santos Vara (2018); Soler García (2017), y Acosta Sánchez (2016).

32 El art. 13 del Reglamento 2016/1624 prevé que el Consejo de Administración de la nueva Agencia Europea de la Guardia de Fronteras y Costas podrá hacer una evaluación de la vulnerabilidad de un Estado con el objetivo de determinar «[...] la capacidad y la preparación de los Estados miembros para hacer frente a los retos venideros, incluidas las amenazas y los retos actuales y futuros en las fronteras exteriores». 
de la Guardia de Fronteras y Costas o no estaba aplicando las medidas necesarias para hacer frente a la presión sobre sus fronteras. Por ello, el nuevo art. 29.1 permitía, sobre la base de una recomendación del Consejo y como respuesta a la ineficaz gestión de las fronteras exteriores, el restablecimiento temporal de los controles fronterizos internos por un periodo no superior a seis meses que se podía prorrogar durante tres veces en caso de persistencia de las circunstancias que habían llevado a su imposición.

En mayo de 2016, a raíz de la adopción de una recomendación del Consejo $^{33}$, se permitió que Austria (en su frontera terrestre con Hungría y con Eslovenia), Alemania (en su frontera terrestre con Austria), Dinamarca (en su frontera terrestre con Alemania y en los puertos daneses con enlaces con puertos alemanes), Suecia (en el puente de OOresund que conecta con Dinamarca, y en los puertos meridionales y occidentales) y Noruega (en los puertos con enlaces con Dinamarca, Alemania y Suecia) mantuvieran ${ }^{34}$, por un periodo máximo de seis meses, determinados controles fronterizos después de que la Comisión evaluase y constatase ${ }^{35}$ que en Grecia existían deficiencias graves en la realización de los controles en sus fronteras exteriores, lo cual ponía en

33 Decisión de ejecución 2016/894 del Consejo, de 12 de mayo de 2016, por la que se establece una Recomendación de realización de controles temporales en las fronteras interiores en circunstancias excepcionales que pongan en peligro el funcionamiento global del espacio Schengen (DO L 151, de 8 de junio de 2016). En relación con esta decisión, véase Acosta Penco (2017).

34 Estos países, con anterioridad a la introducción de este supuesto de suspensión temporal de los controles fronterizos, ya controlaban sus fronteras al considerar que la llegada masiva de inmigrantes suponía una amenaza a su orden público y seguridad interior a la cual era necesario dar una respuesta inmediata. Alemania alegaba que "[...] la afluencia masiva de migrantes irregulares que no han sido debidamente identificados, a quienes no se les han tomado las impresiones dactilares y que no han sido registrados en ningún otro Estado miembro a su llegada a la UE» era una amenaza grave a su seguridad interna y orden público; Austria justificaba los controles fronterizos por la "[...] presión extrema sobre los servicios de emergencia y las infraestructuras públicas»; Suecia consideraba que los flujos migratorios sin precedentes creaban "[...] dificultades para el buen funcionamiento de la sociedad sueca»; Noruega basó el restablecimiento de controles fronterizos en «[...] las consecuencias imprevisibles de la presión migratoria y los consiguientes retos para el funcionamiento de la sociedad noruega", mientras que la decisión de Dinamarca estaba motivada por «[...] los inesperados flujos migratorios y las medidas fronterizas adoptadas por los países vecinos, lo que podría dar lugar a que un gran número de migrantes ilegales quedaran abandonados en la zona de Copenhague» [COM (2016) 275 final, de 4 de mayo de 2016, p. 4].

35 C (2016) 450, de 2 de febrero de 2016. 
peligro el funcionamiento global del espacio Schengen. El Consejo pedía a estos Estados que los controles fuesen lo más «[...] específico y limitado en su alcance, frecuencia, localización y duración a lo estrictamente necesario para responder a la amenaza grave y salvaguardar el orden público y la seguridad interior».

Antes de que expirase el periodo máximo de seis meses, el Consejo recomendó extender los controles fronterizos tres meses más, pues se consideraba que, si bien se había producido una drástica reducción del número de llegadas de migrantes irregulares y de solicitantes de asilo (fruto de la aplicación de la Declaración UE-Turquía de 18 de marzo de 2016 y de las operaciones llevadas a cabo por FRONTEX y la OTAN en el Mediterráneo) resultaba «[...] justificado suponer que estas personas quieran desplazarse irregularmente a otros Estados miembros cuando se supriman los controles fronterizos, que obstaculizan sus movimientos secundarios» ${ }^{36}$. Esta renovación del restablecimiento de los controles en determinados puestos fronterizos no fue suficiente, a pesar de su carácter excepcional, para atenuar la amenaza para el orden público y la seguridad interior de los cinco países que parecían verse directamente afectados por la falta de diligencia de Grecia en el control de sus fronteras exteriores y, por ello, en febrero de 2017, el Consejo volvió a recomendar, a través de una «Decisión de ejecución»" ${ }^{37}$, la prórroga de los controles fronterizos por un nuevo periodo máximo de tres meses. Al finalizar este nuevo periodo de prórroga, el Consejo volvió a considerar que persistían las circunstancias excepcionales en el control de las fronteras exteriores y prorrogó por seis meses más (las dos últimas prórrogas habían sido de tres meses) la suspensión de la libre circulación de personas en determinados puestos fronterizos de Austria, Alemania, Dinamarca, Suecia y Noruega ${ }^{38}$.

36 Decisión de ejecución 2016/1989 del Consejo, de 11 de noviembre de 2016, por la que se establece una Recomendación para prorrogar la realización de controles temporales en las fronteras interiores en circunstancias excepcionales que pongan en peligro el funcionamiento global del espacio Schengen (DO L 306, de 15 de noviembre de 2016, considerando 5, p. 13).

37 Decisión de ejecución 2017/246 del Consejo, de 7 de febrero de 2017, por la que se establece una Recomendación para prorrogar la realización de controles temporales en las fronteras interiores en circunstancias excepcionales que pongan en peligro el funcionamiento global del espacio Schengen (DO L 36, de 11 de febrero de 2017). Decisión de ejecución 2017/818 del Consejo, de 11 de mayo de 2017, por la que se establece una Recomendación para prorrogar la realización de controles temporales en las fronteras interiores en circunstancias excepcionales que pongan en peligro el funcionamiento global del espacio Schengen (DO L 122, de 13 de mayo de 2017). 


\section{LA ACTUALIZACIÓN DE LA REGULACIÓN RELATIVA AL RESTABLECIMIENTO DE LOS CONTROLES FRONTERIZOS: EL REFORZAMIENTO DE LOS CONTROLES POLICIALES Y LA PROLONGACIÓN DE LOS PLAZOS}

Si bien, como hemos visto, se han producido numerosos casos de restablecimiento de los controles fronterizos que se han planteado esencialmente como una respuesta a la amenaza que los movimientos secundarios de migrantes representaban para el orden público y la seguridad interior de los Estados del espacio Schengen, persiste a fecha de hoy una percepción de vulnerabilidad que se vincula con la ausencia de controles fronterizos y el riesgo de que se cometan actos terroristas en territorio europeo. Cabe recordar que, en los últimos dos años, Alemania, Bélgica, Dinamarca, España, Finlandia, Francia, Suecia y el Reino Unido han sufrido atentados terroristas. También es cierto que solo Francia (que entre enero de 2015 y abril de 2017 sufrió diez atentados terroristas, lo cual pone de relieve la intensidad de dichos ataques) ha restablecido los controles fronterizos como respuesta a dicha amenaza, mientras que el resto de los Estados no lo han hecho.

A pesar de su carácter y naturaleza excepcional, lo cierto es que, en los últimos dos años (entre octubre de 2015 y octubre de 2017), los controles fronterizos se han restablecido y prorrogado casi cincuenta veces, mientras que, en el periodo 2006-2015, se plantearon 36 casos de restablecimiento de fronteras ${ }^{39}$. Si bien esta práctica reiterada sobre el restablecimiento temporal de los controles fronterizos pone en cuestión la esencia misma de Schengen en la medida en que los Estados pasan a controlar la entrada de personas en su territorio, recientemente la Comisión ha propuesto la adopción de una serie de medidas dirigidas al reforzamiento del espacio Schengen destinadas precisamente a garantizar su continuidad.

Por una parte, la Comisión ha hecho especial énfasis en la necesidad de intensificar y mejorar los controles policiales y la cooperación policial como una vía para evitar el restablecimiento de los controles fronterizos. Por otra, se ha propuesto la modificación de la regulación del Código de Fronteras Schengen con el objetivo de actualizar los plazos permitidos para prolongar los controles fronterizos tanto en los supuestos previsibles como en los supuestos que exijan una respuesta inmediata, lo cual pasa por alargar los plazos existentes

39 Exposición de motivos de la propuesta de reglamento que modifica el Reglamento $2016 / 399$ en lo que respecta a las normas aplicables al restablecimiento temporal de controles fronterizos en las fronteras interiores [COM (2017) 571 final, de 27 de septiembre de 2017, p. 2]. 
hasta ahora y dotar de una mayor garantía al procedimiento existente de restablecimiento de fronteras ${ }^{40}$.

\section{LOS CONTROLES POLICIALES Y LA COOPERACIÓN POLICIAL COMO VÍAS ALTERNATIVAS AL RESTABLECIMIENTO DE LOS CONTROLES FRONTERIZOS}

La constatación de que, a pesar de que el restablecimiento de los controles fronterizos debería ser excepcional y configurarse como el último recurso al cual acuden los Estados para preservar el orden público y la seguridad interior, estos han suspendido en múltiples ocasiones la libre circulación de personas ha hecho que, desde 2017, se haya puesto especial énfasis en una cuestión que no se había planteado hasta el momento: la necesidad de reforzar los controles policiales en el interior de los Estados y la cooperación policial como una vía alternativa para hacer frente de forma preventiva a las amenazas al orden público y a la seguridad interior a las que también el restablecimiento de los controles fronterizos constituye una respuesta.

El 3 de octubre de 2017, la Comisión adoptó una recomendación dirigida a los ventiséis Estados del espacio Schengen en la que les sugería que, antes de restablecer los controles fronterizos, era necesario usar otras medidas alternativas menos costosas que no implicasen una restricción a la libre circulación de personas como el refuerzo de los controles policiales proporcionados y la cooperación policial ${ }^{41}$. Anteriormente, la Comisión ya había incidido, en una recomendación de 12 de mayo de 2017, en que los Estados debían, atendiendo a la excepcionalidad del restablecimiento de controles fronterizos, dar prioridad a los controles de policía en caso de amenaza grave para el orden público o la seguridad interior ${ }^{42}$. Ciertamente, la intensificación de los controles policiales y de las distintas iniciativas de cooperación policial (patrullas policiales fronterizas conjuntas o intercambio de información transfronterizo) puede ayudar especialmente a evitar el restablecimiento de fronteras en casos previsibles. El problema relevante que plantea el reforzamiento de los con-

40 Comunicación de la Comisión sobre la protección y el refuerzo de Schengen [COM (2017) 570 final, de 27 de septiembre de 2017].

41 Recomendación 2017/1804 de la Comisión, de 3 de octubre de 2017, relativa a la aplicación de las disposiciones del Código de fronteras Schengen sobre la reintroducción temporal de controles fronterizos en las fronteras interiores en el espacio Schengen (DO L 259, de 7 de octubre de 2017).

42 Recomendación 2017/820 de la Comisión, de 12 de mayo de 2017, sobre los controles policiales proporcionados y la cooperación policial en el espacio Schengen (DO L 122, de 13 de mayo de 2017). 
troles policiales como vía alternativa a la suspensión de la libre circulación de personas es determinar en qué medida dichos controles sobre las personas pueden equivaler a inspecciones fronterizas encubiertas. El Código de Fronteras Schengen prohíbe no solo los controles fronterizos, sino también las medidas que tengan un efecto equivalente a éstas.

Ya en 2006, cuando entró en vigor el Código de Fronteras Schengen, se regularon de forma específica (art. 21 del Reglamento 562/2006) distintas cuestiones relacionadas con la potestad de la policía de llevar a cabo inspecciones dentro del territorio con el objetivo de determinar en qué supuestos dichos controles no equivaldrían a inspecciones fronterizas (las inspecciones no debían tener como objetivo el control de fronteras, debían estar basadas en información de carácter general y destinadas a combatir la delincuencia transfronteriza, debían estar concebidas y ser ejecutadas de un modo diferenciado de las inspecciones sistemáticas de personas en las fronteras exteriores y llevarse a cabo de forma general, aleatoria y no discriminatoria). La actual regulación del Código mantiene la normativa relativa a las inspecciones dentro del territorio Schengen por la policía en estos mismos términos.

El TJUE ha tenido ocasión de pronunciarse sobre el contenido y los límites de los controles policiales llevados a cabo en frontera y su compatibilidad con el Código de Fronteras Schengen. En el asunto Melki y Abdeli de 2010, a raíz de la detención de dos nacionales argelinos en situación irregular en Francia en una zona situada a veinte kilómetros de la frontera con Bélgica, la Corte francesa de Casación planteó una cuestión prejudicial en la que se solicitaba al TJUE que determinase si la normativa francesa que permitía a la policía controlar, en una zona de veinte kilómetros desde la frontera terrestre con otro Estado, la identidad de cualquier persona, con independencia del comportamiento de esta y de circunstancias específicas que acrediten el riesgo de perturbación del orden público, para saber si llevaba consigo la documentación pertinente obligatoria era o no compatible con la libre circulación de personas y con el Código. Se trataba de valorar, por tanto, el margen de discrecionalidad con que contaban los cuerpos policiales a la hora de llevar a cabo controles no específicos en el territorio de un Estado cercano a la frontera.

El TJUE consideró que la regulación era contraria a la libre circulación de personas puesto que la competencia atribuida a la policía era muy general y se debía "[...] prever la necesaria delimitación de la competencia atribuida a esas autoridades, en particular a fin de orientar la facultad de apreciación de la que disponen estas últimas en la aplicación práctica de dicha competencia» ${ }^{43}$.

43 Sentencia de 22 de junio de 2010, Melki y Abdeli, C-188/10 y C-189/10, EU:C:2010: 363, apdo. 74. En esta línea, el abogado general Mazák señaló en sus conclusiones 
Evidentemente, razones de seguridad y de mantenimiento del orden público exigen que los cuerpos policiales puedan controlar a las personas que estén en el territorio del Estado, pero su actuación no puede equivaler a inspecciones fronterizas encubiertas. En este sentido, las atribuciones hechas a la policía francesa podían entenderse como tales en la medida en que, por una parte, la competencia se limitaba a la zona fronteriza y, por otra, podía ejercerse con independencia del comportamiento de la persona controlada y de circunstancias específicas que acreditasen un riesgo de perturbación del orden público. Por ello, el TJUE entendió que el Código de Fronteras Schengen exigía que el derecho interno delimitase la competencia atribuida a la policía, esto es, que previese precisiones y limitaciones de la competencia conferida para impedir la posibilidad de que dicha competencia se ejerza sin ningún tipo de limitación y de forma discrecional de tal manera que equivalga a un control fronterizo encubierto.

Esta misma cuestión se volvió a plantear en 2012 ante el TJUE en el asunto $A d i l^{44}$. En este caso, a raíz de una cuestión prejudicial planteada por un tribunal holandés en que se solicitaba al Tribunal de Justicia que determinase si determinados artículos del decreto holandés de extranjería (modificado precisamente al hilo del asunto Melki y Abdeli), que permitían controles sobre las personas a efectos de combatir la estancia irregular una vez traspasada la frontera, equivalían a controles fronterizos encubiertos. El litigio tenía su origen en la detención del Sr. Adil, nacional afgano, cuando se encontraba como pasajero a bordo de un autobús en una zona de veinte kilómetros medida a partir de la frontera con Alemania. Este cuestionó la legalidad, conforme al Código de Fronteras Schengen, del control realizado que llevó a su posterior detención e internamiento en un centro para inmigrantes ilegales, pues en el momento del control no existía, por lo que a él respectaba, una presunción razonable de estancia irregular. Se planteaba, por tanto, si las competencias atribuidas por la legislación holandesa sobre extranjería a los funcionarios encargados de la vigilancia de las fronteras y del control de los extranjeros que les permitían realizar controles en una zona geográfica de veinte kilómetros a

sobre ambos asuntos que «[...] los eventuales controles del cumplimiento de la obligación de poseer o llevar consigo documentos pueden constituir, en función de las circunstancias, un obstáculo al principio general de la supresión del control en las fronteras interiores, en particular, cuando dichos controles se realizan de forma sistemática, arbitraria o inútilmente severa» (Conclusiones presentadas el 7 de junio de 2010 en el asunto C-188/10 y C-189/10, EU:C:2010:319, apdo. 46).

Sentencia de 19 de julio de 2012, Adil, C-278/12 PPU, EU:C:2012:508. 
partir de la frontera terrestre con otro Estado era compatible con la supresión de controles fronterizos previsto en el Código.

Después de analizar la naturaleza, objetivos y considerar que no eran controles generales, sino precisos y determinados basados en información general y sujetos a una determinada intensidad y frecuencia, el TJUE afirmó la compatibilidad de los controles realizados en la frontera para combatir la inmigración irregular, pues, como exigió en la sentencia Melki y Abdeli, la normativa neerlandesa

[...] establece precisiones y limitaciones por lo que atañe al ejercicio de las competencias de policía que atribuye a las autoridades competentes del Estado miembro de que se trata. Además, esas precisiones y limitaciones posibilitan que se condicione la intensidad y la frecuencia de los controles que pueden realizar en la zona fronteriza esas autoridades y tienen por objeto orientar la facultad de apreciación de que disponen estas últimas en el ejercicio práctico de su competencia ${ }^{45}$.

La exigencia de que los controles policiales estén sujetos a precisiones y limitaciones que determinen la intensidad, la frecuencia y su carácter selectivo para que no sean considerados controles encubiertos a la libre circulación de personas se ha vuelto a plantear recientemente ante el TJUE en el asunto $A^{46}$. En esta sentencia, el órgano jurisdiccional de la Unión resolvió dos cuestiones prejudiciales planteadas por un tribunal alemán a raíz de la detención por la policía federal alemana de un ciudadano alemán en la estación de tren (situada a quinientos metros de la frontera) de la ciudad fronteriza de Kehl, a la cual el detenido había accedido después de cruzar el puente que une dicha ciudad con la ciudad francesa de Estrasburgo. El ciudadano alemán fue requerido por la policía para que se identificase, a lo que este se negó haciendo uso de la violencia, fue detenido y acusado de cometer un delito de resistencia a un agente de la fuerza pública tipificado en el Código Penal alemán. El tribunal de instancia consideró que sí se había cometido un delito de resistencia a un

45 Apartado 87. En términos similares se pronunció la abogada general SHARPSTON en sus conclusiones en este asunto al afirmar que el Código de Fronteras Schengen «(...) no se opone a que la normativa nacional prevea que tales detenciones se realicen, bien sobre la base de la información general y de la experiencia obtenidas en materia de estancia irregular, sin que deban venir motivadas por el comportamiento del afectado o por circunstancias específicas que acrediten un riesgo de perturbación del orden público, bien en razón de la necesidad de obtener información en materia de estancia irregular una vez atravesada la frontera» (conclusiones presentadas el 9 de julio de 2012 en el asunto C-278/12 PPU, EU:C:2012:430, apartado 81).

46 Sentencia del Tribunal de Justicia de 21 de junio de 2017, A, C-9/16, EU:C:2017:483. 
agente de la fuerza público, pero tenía dudas de si el control de identidad realizado por la policía era conforme con el Código de Fronteras Schengen y, por tanto, lícito.

La regulación prevista en el apartado sobre la protección de las fronteras y de competencias de la Ley de Policía Federal, por una parte, permitía a la policía identificar a cualquier persona, con independencia de su comportamiento y de la existencia de circunstancias especiales, en una zona de treinta kilómetros desde la frontera para poner fin a la entrada ilícita en el territorio o para prevenir determinados delitos contra la seguridad de las fronteras. Por otra parte, se permitía dar el alto, interrogar y exigir la documentación en el recinto de las instalaciones ferroviarias a cualquier persona a fin de prevenir o poner fin a la entrada ilícita en Alemania en caso de sospechas fundadas. En el primer supuesto, el TJUE, al hilo de la jurisprudencia iniciada en el caso Melki y Abdeli, observó que la Ley de Policía Federal no contenía ni precisiones ni limitaciones a la competencia de las autoridades en relación con la intensidad y la frecuencia de los controles y, por ello, cabía pensar que dichos controles tenían un efecto equivalente a las inspecciones fronterizas. Resultaba excesivamente abstracto autorizar controles sobre las personas con independencia del comportamiento de la persona en cuestión y de la concurrencia de circunstancias que revelasen un riesgo de perturbación del orden público. En todo caso, era competencia del órgano judicial que había planteado la cuestión prejudicial hacer una valoración concreta del supuesto previsto en la ley. En relación con los controles en las instalaciones ferroviarias, el TJUE consideró que estos eran compatibles con el Código de Fronteras Schengen «[...] siempre que el ejercicio de tales controles quede sujeto en el derecho nacional a precisiones y limitaciones que determinen la intensidad, la frecuencia y el carácter selectivo de tales controles, que incumbe comprobar al órgano jurisdiccional remitente» (apdo. 75).

En todo caso, no solo los controles policiales pueden equivaler a inspecciones fronterizas encubiertas. Actualmente, está pendiente ante el TJUE una cuestión prejudicial planteada el 10 de julio de 2017 por el Tribunal Supremo de lo Contencioso-Administrativo de Alemania en que este solicita que se determine si la exigencia prevista en una ley alemana a las empresas de transporte en autocar que ofrecen servicios regulares transfronterizos dentro del espacio Schengen de que comprueben, antes de cruzar una frontera interna, que los pasajeros poseen los documentos de viaje necesarios para entrar en Alemania y la imposición de una sanción en caso de incumplimiento es compatible con el art. 67 del TFUE y con los arts. 20 y 21 del Código de Fronteras Schengen en la medida en que pueden constituir una medida con un efecto equivalente 
a una inspección fronteriza ${ }^{47}$. A juicio del abogado general Bot, estos controles por parte de las empresas de transporte que impone la Ley de residencia, trabajo e integración de los extranjeros en el territorio federal de 30 de julio de 2004 se pueden equiparar a inspecciones fronterizas prohibidas por el art. 20 del Código de Fronteras Schengen en la medida en que «[...] el Estado miembro exige a operadores privados que lleven a cabo unos controles que las autoridades nacionales competentes ya no están autorizadas a realizar en las fronteras interiores» ${ }^{48}$.

\section{LA PROLONGACIÓN DE LOS PLAZOS DEL RESTABLECIMIENTO TEMPORAL DE LOS CONTROLES FRONTERIZOS}

A juicio de la Comisión, los supuestos que se han planteado en los dos últimos años de restablecimiento de los controles fronterizos «[...] han demostrado no estar suficientemente adaptados para responder a las crecientes amenazas para el orden público o la seguridad interior»y, por ello, ha planteado recientemente una propuesta de modificación del Código de Fronteras Schengen dirigida, por una parte, a establecer un nuevo procedimiento y nuevos plazos en caso de querer prorrogar los controles fronterizos y, por otra, fomentar el recurso a medidas alternativas para mitigar las amenazas existentes para evitar la suspensión de la libre circulación de personas que debe ser el último recurso ${ }^{49}$.

En relación con la propuesta de la Comisión, cabe señalar que esta solo incide en el supuesto de restablecimiento de los controles fronterizos en casos previsibles (al que se ha acudido en contadas ocasiones), pero no modifica el supuesto ni los plazos en caso de restablecimiento inmediato, ni tampoco modifica el supuesto que ha tenido una mayor virtualidad práctica durante estos dos últimos años que es el relativo a la existencia de deficiencias graves persistentes en los controles de las fronteras exteriores.

47 Estas dos cuestiones se plantearon a raíz de la impugnación de las órdenes dictadas por la Dirección de la Policía Federal, por las que se prohibía a ambas empresas transportar en territorio alemán extranjeros que no dispusiesen de pasaporte y de permiso de residencia y se les apercibía de la imposición de una multa coercitiva por importe de 1.000 euros por extranjero en caso de incumplimiento de esta prohibición.

48 Conclusiones presentadas el 6 de septiembre de 2018 en los asuntos acumulados C-412/17 y C-474/17, Touring Tours und Travel y Sociedad de Transportes, EU:C:2018:671, apdo. 100.

49 Propuesta de reglamento que modifica el Reglamento 2016/399 en lo que respecta a las normas aplicables al restablecimiento temporal de controles fronterizos en las fronteras interiores [COM (2017) 571 final, de 27 de septiembre de 2017]. 
En el supuesto de restablecimiento temporal de los controles fronterizos en caso de acontecimientos previsibles, se propone la modificación del apdo. 4 del actual art. 25 del Código de Fronteras Schengen para permitir que la duración de la suspensión de la libre circulación de personas pase del máximo actual de seis meses a un nuevo máximo de un año ${ }^{50}$. Asimismo, y a fin de que la duración de los periodos renovables sea más proporcionada a la duración total máxima de los controles fronterizos, los periodos renovables pasan de treinta días a seis meses renovables hasta un máximo de un año ${ }^{51}$. Con el objetivo de que la Comisión controle más la decisión de un Estado de establecer los controles fronterizos y prorrogarlos, se introduce una nueva obligación de los Estados de presentar al resto de Estados una evaluación de los riesgos (tiempo que se considere que persistirá la amenaza detectada, partes de la frontera que se verán afectadas, demostración de que la prórroga es una medida de último recurso y explicación sobre de qué manera el control de fronteras contribuirá a abordar la amenaza detectada) y de que el Estado que imponga los controles se coordine con los Estados con los que comparte fronteras. La nueva regulación propuesta otorga un papel activo a Europol y a la Agencia Europea de la Guardia de Fronteras y Costas en la valoración de los riesgos y de las amenazas. Los Estados que superen el periodo de seis meses de suspensión de la libre circulación de personas deberán demostrar a posteriori que dicha suspensión contribuyó a hacer frente a la amenaza detectada.

La propuesta de modificación del Código de Fronteras Schengen introduce otra novedad relevante, que es la introducción de un nuevo art. 27 bis que prevé un procedimiento específico en caso de que la amenaza grave para el orden público o la seguridad interior exceda de un año (el máximo previsto en caso de acontecimientos previsibles). Este nuevo supuesto ha de ser excepcional y se basa en la constatación de que el Estado ha tomado medidas

50 En la exposición de motivos, la Comisión observa que la práctica ha puesto de manifiesto que las amenazas graves para el orden público o la seguridad interior (y pone como ejemplo las amenazas terroristas transfronterizas o los movimientos secundarios de migrantes irregulares) pueden persistir más allá de los plazos previstos de suspensión de la libre circulación de personas en vigor y, de ahí, la necesidad de extenderlos (Ibid., p. 13).

51 La propuesta de la Comisión se basa en la propuesta de modificación del art. 25 del Código de Fronteras Schengen presentada el 5 de septiembre de 2017 por Austria, Dinamarca, Francia, Alemania y Noruega. Dicha propuesta no fue totalmente acogida por la Comisión, puesto que estos Estados proponían que los plazos pasasen de treinta días a tres meses hasta un plazo máximo de dos años (Proposal for a targeted amendment to article 25 of the Schengen Borders Code concerning the re-establishment of internal border controls, p. 2). 
«excepcionales proporcionadas» a escala nacional para hacer frente a la persistencia de una amenaza grave para el orden público y la seguridad interior ${ }^{52}$. En estos casos, seis semanas antes de que finalice el plazo de un año, el Estado que se enfrente a estas circunstancias excepcionales deberá notificarlo al resto de Estados y a la Comisión. Ésta deberá emitir un dictamen y el Consejo podrá recomendar al Estado la prórroga de los controles fronterizos por un periodo de seis meses más. Ese nuevo periodo podrá ser prorrogado a su vez en tres ocasiones por periodos de seis meses, exigiéndose al Estado en cuestión que facilite un conjunto de información sobre los motivos y alcance de los controles. De esta manera, se puede llegar a la suspensión de la libre circulación de personas durante un plazo máximo de dos años. Este plazo máximo también se mantiene en relación con el supuesto de existencia de circunstancias excepcionales que pongan en riesgo el funcionamiento general del espacio sin controles en las fronteras interiores.

La propuesta de la Comisión introduce, por tanto, la posibilidad de mantener durante un máximo de un año la suspensión de la libre circulación de personas en caso de amenazas graves para el orden público y la seguridad interior que sean previsibles. Y parece, a juicio de la Comisión, que las amenazas terroristas transfronterizas y los movimientos secundarios de migrantes irregulares han adquirido una naturaleza persistente que justifica su invocación por parte de los Estados. Asimismo, se introduce la novedad de permitir el restablecimiento de los controles fronterizos por un máximo de dos años en caso de que un Estado adopte medidas internas excepcionales para hacer frente a amenazas a su orden público o seguridad interior y se mantiene el plazo máximo de dos años que ya existía en el supuesto de que concurran circunstancias excepcionales que pongan en riesgo el funcionamiento general del espacio sin fronteras interiores como consecuencia de deficiencias graves persistentes en los controles en las fronteras exteriores de la Unión. Se pretende, por tanto, una prolongación de los plazos en caso de amenazas previsibles hasta un máximo de un año y se unifican a un máximo de dos años tanto la suspensión de la libre circulación de personas en caso de adopción de medidas internas excepcionales como en caso de deficiencias en las fronteras exteriores.

52 En la exposición de motivos de la propuesta de modificación del reglamento, la Comisión pone como ejemplo de situación excepcional que se haya decretado «el estado de emergencia» (Ibid., p. 10). De esta manera, en el caso español, el supuesto sería reconducible a cualquiera de los tres grados de estados de emergencia o regímenes de excepción previstos en el artículo 116 de la Constitución: estado de alarma, de excepción y de sitio. 


\section{EL CONTROL JUDICIAL INTERNO DE LA DECISIÓN DE PRORROGAR LOS CONTROLES FRONTERIZOS: LA SENTENCIA DE 28 DE DICIEMBRE DE 2017 DEL CONSEJO DE ESTADO FRANCÉS}

Francia ha sido el país del espacio Schengen que ha mantenido durante más tiempo los controles fronterizos. De hecho, desde que el 13 de noviembre de 2015 decidiese el restablecimiento de los controles en sus fronteras con motivo de la celebración en París de la conferencia sobre cambio climático, diversos atentados terroristas cometidos en territorio francés y algún evento deportivo han hecho que Francia haya extendido o renovado nueve veces la decisión de imponer por motivos de orden público y seguridad interior los controles fronterizos. Ello ha supuesto la suspensión, si bien no de forma consecutiva, de la libre circulación de personas por un periodo total de dos años, cinco meses y quince días.

El 3 de octubre de 2017, conforme a lo dispuesto en los arts. 25 y 27 del Reglamento 2016/399, el Gobierno francés notificó a la secretaria general del Consejo su intención de restablecer los controles fronterizos entre el 1 de noviembre de 2017 y el 30 de abril de 2018. Tres ONG francesas que trabajaban con inmigrantes decidieron impugnar ante el Consejo de Estado la última decisión del Gobierno francés de restablecer los controles fronterizos al entender que esta era contraria a lo dispuesto en el art. 25 del Reglamento 2016/399. En su demanda, las ONG solicitaban al Consejo de Estado: a) que anulase, por desviación de poder, la decisión gubernamental de prolongar los controles fronterizos terrestres y marítimos con los países vecinos; b) que el Consejo de Estado plantease ante el TJUE un cuestión prejudicial al entender que la decisión de prorrogar los controles fronterizos era contraria al Reglamento 2016/399 y a lo dispuesto en los arts. 18 (derecho de asilo) y 45 (libertad de circulación y residencia) de la Carta de Derechos Fundamentales de la UE, y c) solicitar el pago de 2000 euros en concepto de costas ${ }^{53}$.

A juicio de las ONG, teniendo en cuenta que el art. 25 del Reglamento 2016/399 establece inicialmente que el restablecimiento de controles fronterizos debe plantearse por un periodo de treinta días prorrogables hasta un máximo que no puede superar los seis meses, el Gobierno francés no podía volver a plantear una nueva prórroga de los controles fronterizos (que se restablecieron inicialmente el 13 de noviembre de 2015), pues se había excedido claramente el plazo máximo de seis meses. Las autoridades francesas basaban su decisión

53 Conseil d'État, 28 décembre 2017, Association nationale d'assistance aux frontières pour les étrangers et autres, n. ${ }^{o} 415291$ (disponible en: www.conseil-etat.fr). 
en consideraciones de seguridad interior y orden público y estas habían estado presentes en las diferentes prórrogas de los controles fronterizos que se habían producido. La cuestión era determinar si, siendo la amenaza a la seguridad interior y al orden público la misma en todos los casos, el plazo máximo no podía exceder de seis meses. Al plantearse dudas sobre la interpretación del plazo previsto en el art. 25 del Reglamento 2016/399, las ONG también solicitaban que el Consejo de Estado, al ser tribunal de última instancia, presentase una cuestión prejudicial ante el TJUE para darle la posibilidad de que se pronunciase por primera vez sobre el sentido del plazo máximo previsto en dicho artículo.

El Consejo de Estado no acoge ninguna de las pretensiones que se le plantean y razona básicamente que, dado el elevado riesgo de que se cometan actos terroristas en Francia, motivos de orden público y seguridad interior justifican claramente que el Gobierno francés decida establecer nuevos periodos de control en sus fronteras. El Consejo de Estado entiende que el plazo de seis meses no puede entenderse como un plazo máximo aunque las amenazas sean las mismas y que Francia, en caso de nuevas o renovadas amenazas a su seguridad interior y orden público, puede volver a restablecer los controles fronterizos empezando a contar nuevamente el tiempo de cómputo ${ }^{54}$. Por otra parte, también entiende que la decisión impugnada es proporcional a las amenazas existentes y, por tanto, ello no supone una vulneración ni del derecho a solicitar asilo ni del derecho de libre circulación. A su vez, la gravedad de las amenazas al orden público y seguridad interior hace que no se cumplan los requisitos de la figura de la desviación de poder en la medida en que dicha gravedad justifica claramente la decisión gubernamental. En consecuencia, tampoco se condena en costas a la parte demandada.

La decisión del Consejo de Estado ha sido objeto de crítica. En este sentido, Platon (2018) considera que, teniendo en cuenta que la amenaza al orden público y a la seguridad interior no es nueva, pues ya se invocó en 2015 a la hora de restablecer los controles fronterizos, la suspensión a la libre circulación de personas no podía exceder los seis meses previstos en el art. 25 del Reglamento 2016/399. Este autor también entiende que el Consejo de Estado debería haber planteado una cuestión prejudicial al existir una «legitimate doubt» sobre la interpretación del art. 25.4 del Código de Fronteras Schengen, no siendo aplicable la doctrina del acto claro. Este autor afirma también que el

54 En este sentido, afirma que «[...] si l'article 25 précité limite la durée maximale de la réintroduction d'un contrôle aux frontières intérieures à six mois, il ne fait pas obstacle, en cas de nouvelle menace ou de menace renouvelée pour l'ordre public ou la sécurité intérieure, à la mise en place à nouveau d'un contrôle aux frontières pour une autre période d'une durée maximale de 6 mois» (FJ 7). 
Consejo de Estado ha hecho prevalecer consideraciones de seguridad pública para justificar la decisión del Gobierno francés y que, a su juicio, las tres últimas renovaciones del plazo de seis meses que ha recomendado el Consejo de la Unión debido a la existencia de deficiencias en las fronteras exteriores ponen de manifiesto que los seis meses son un plazo máximo que se debe renovar hasta el máximo de dos años permitido por el Código. Este último supuesto, aplicable en caso de deficiencias en las fronteras exteriores de la Unión, no es aplicable al caso, pero lleva a entender el carácter vinculante de los plazos máximos fijados por el Código. Cassia (2017) también ha criticado en términos similares la decisión del Consejo de Estado; ha señalado que las sucesivas prórrogas por parte de Francia de los controles fronterizos no han impedido la comisión de atentados terroristas y que quizás, para preservar la integridad del espacio Schengen y la libre circulación de personas, el Consejo de Estado, a la hora de avalar la legalidad de la decisión impugnada, debería haber tenido en cuenta el reforzamiento de los controles de las fronteras exteriores de la Unión llevado a cabo en el marco del Código de Fronteras Schengen.

Hubiese sido deseable que, teniendo en cuenta que se planteaba por primera vez un control de legalidad de una decisión de un Estado de prorrogar los controles fronterizos, el Consejo de Estado hubiese planteado una cuestión prejudicial ante el TJUE para que este se pronunciase sobre su compatibilidad con el Código de Fronteras Schengen. Así se habrían despejado dudas y se habría dado mayor claridad y seguridad a las iniciativas nacionales de imponer controles fronterizos al determinar la interpretación que debía darse a los plazos máximos permitidos por el Código. Ciertamente, cualquier Estado está obligado a salvaguardar a su población de las amenazas a su orden público y a su seguridad interior que se puedan plantear y, por ello, tiene sentido entender que se pretenda que el cómputo del restablecimiento de los controles fronterizos se vuelva a iniciar cuando la anterior prórroga ha finalizado, pues, de lo contrario, se podría dejar a la población desprotegida frente a dichas amenazas, lo cual difícilmente se podría justificar ante la opinión pública. Ahora bien, ello también plantea dudas puesto que la regulación actual de las prórrogas en los distintos supuestos previstos y el procedimiento a seguir pueden llevar a pensar que, dado su carácter excepcional, los controles fronterizos y sus prórrogas no pueden ir más allá de un máximo establecido, pues, de lo contrario, el principio de libre circulación de personas se vería claramente desvirtuado.

\section{CONSIDERACIONES FINALES}

El restablecimiento y prórroga de los controles fronterizos en casi cincuenta ocasiones estos dos últimos años pone de manifiesto la quiebra de un 
elemento que forma parte de la esencia del espacio Schengen: el principio de confianza mutua. Desde sus orígenes, la eliminación de los controles fronterizos entre Estados con el objetivo de hacer efectiva la libre circulación de personas se basaba en la premisa de que los Estados, especialmente aquellos que contaban con fronteras exteriores, las controlaban de forma diligente y efectiva y, de ahí, que el resto de Estados confiara en dicha labor. Si había un control real sobre las personas que entraban en el espacio Schengen, no tenía sentido que el resto de Estados se planteasen limitar la entrada de personas en su territorio, pues cabía entender que estas ya habían sido controladas al acceder a dicho espacio. Esa era la esencia de un proyecto compartido por todos. Parecía que los Estados aceptaban dicho principio, aun a riesgo de que podían existir amenazas que afectasen a su orden público y seguridad interior.

Durante los años noventa, distintos países (entre ellos, España) padecieron la lacra del terrorismo y ello no implicó el recurso reiterado a la cláusula de suspensión prevista en el sistema Schengen, como ha sucedido en los últimos tiempos como consecuencia de distintas amenazas terroristas. Además, en muchas ocasiones los autores de dichos actos delictivos eran nacionales del mismo Estado en el cual se cometían los atentados. No eran personas que habían accedido al espacio Schengen desde el exterior. Es cierto también que la presión migratoria ha sido muy fuerte estos últimos años, pero se han creado mecanismos como la Guardia Europea de Fronteras y Costas y otros mecanismos de apoyo a los Estados que han tenido que hacer frente a los flujos migratorios en los cuales quizás el resto de Estados debería haber confiado más antes de proceder al restablecimiento de controles fronterizos. El drama del proyecto europeo ha sido la incapacidad de dar una respuesta conjunta a los problemas vinculados a los flujos migratorios (Collier, 2018). Se han impuesto visiones nacionales de cómo hacer frente a las amenazas y quizás ha faltado épica colectiva a la hora de abordar de forma conjunta un gran desafío que afecta no solo a los países que son frontera exterior, sino al conjunto de países del espacio Schengen. Por otro lado, tampoco se acaba de entender que hayan sido siempre los mismos países los que han suspendido la libre circulación de personas para gestionar de forma correcta los flujos migratorios (Austria, Alemania, Dinamarca, Suecia y Noruega) cuando estos flujos potencialmente también podían afectar al resto de países del espacio Schengen.

El problema esencial reside, evidentemente, en la creciente percepción de vulnerabilidad que tiene la población. Y dicha vulnerabilidad se vincula precisamente al hecho de que, en el espacio Schengen, ante la ausencia de controles fronterizos, los Estados no controlan a las personas que entran en su territorio de tal manera que se percibe que los movimientos de migrantes suponen una amenaza para el orden público y la seguridad interior, del mismo modo que un Estado desconoce el potencial delictivo de las personas que 
entran o están en su territorio que, en determinados casos, puede implicar la realización de actos terroristas.

La Unión ha pretendido ordenar ese intento de renacionalizar las respuestas a las amenazas al orden público y a la seguridad interior haciendo especial énfasis en el carácter excepcional de cualquier limitación que se plantee a la libre circulación de personas. Otorgar un mayor papel a los controles policiales en el interior de los Estados miembros como vía para prevenir amenazas potenciales a la seguridad de los Estados teniendo en cuenta los contornos definidos por el TJUE para que ello no sea una restricción encubierta a la libre circulación de personas, y la propuesta de alargar los plazos máximos de restablecimiento de los controles fronterizos, se configuran como iniciativas dirigidas a intentar preservar la integridad y esencia del espacio Schengen como un gran espacio unificado en el cual las personas puedan circular libremente. El desafío es mayúsculo, más si tenemos en cuenta la relevancia cada vez mayor en determinados Estados de gobiernos (Italia, Hungría, Eslovenia, Eslovaquia o Polonia) con un discurso muy crítico con la integración europea y con la gestión de los flujos migratorios.

\section{Bibliografía}

Acosta Penco, M. T. (2017). Primer caso de restablecimiento de los controles fronterizos en circunstancias excepcionales que ponen en peligro el funcionamiento global del espacio Schengen: comentario a la Decisión de ejecución 2016/894 del Consejo, de 12 de mayo de 2016. Revista General de Derecho Europeo, 41, 252-273.

Acosta Sánchez, M. A. (2016). La nueva Guardia Europea de Fronteras y Costas: una necesaria evolución de FRONTEX. Documento Opinión 108/2016, IEEE, 1-17.

Carrera, S., Guild, E., Merlino, M. y Parkin, J. (2011). A Race against Solidarity: the Schengen Regime and the Franco-Italian Affair. CEPS Liberty and Security in Europe, Working Paper.

Cassia, P. (2017). Le Conseil d'État décode Schengen. Mediapart [blog], 29-12-2017. Disponible en: www.blogs.mediapart.fr/paul-cassia.

Collier, P. (2018). Europa y los refugiados: una tragedia rayana en la farsa. En M. Castells et al. Las crisis de Europa (pp. 331-354). Madrid: Alianza Editorial.

Evard, E., Nienaber, B. y Sommaribas, A. (2018). The temporary reintroduction of border controls inside the Schengen area: towards a spatial perspective. Journal of Borderlands Studies, 1-15. Disponible en: https://doi.org/10.1080/0888656 55.2017.1415164.

Groenendijk, K. (2004). Reinstatement of controls at the internal borders of Europe: why and against whom? European Law Journal, 10 (2), 150-170. Disponible en: https://doi.org/10.1111/j.1468-0386.2004.00209.x. 
Jorgensen, C. Y Sorensen, K. (2012). Internal border controls in the European Union: recent challenges and reforms. European Law Review, 37 (3), 249-268.

Martín Martínez, M. M. (2014). Límites a la libre circulación de personas en la UE por razones de orden público, seguridad o salud pública en tiempos de crisis: una revaluación a la luz de la jurisprudencia del TJUE. Revista de Derecho Comunitario Europeo, 49, 767-804.

Olesti Rayo, A. (2012). El espacio Schengen y la reinstauración de los controles en las fronteras interiores de los Estados miembros de la Unión Europea. Revista d'Estudis Autonòmics i Federals, 15, 44-84.

- (2016). La crisis migratoria y la reinstauración de los controles de las fronteras interiores en el espacio Schengen. Revista Española de Derecho Internacional, 68 (1), 243-247. Disponible en: http://dx.doi.org/10.17103/redi.68.1.2016.4a.06.

Peers, S. (2013). The future of the Schengen system. Stockholm: Swedish Institute for European Policy Studies.

Platon, S. (2018). 30 days, six months...forever? Border control and the French Council of State Verfassungsblog on Matters Constituional [blog], 9-1-2018. Disponible en: https://bit.ly/2NqJTZe.

Santos Vara, J. (2018). La transformación de Frontex en la Agencia Europea de la Guardia de Fronteras y Costas: ¿hacia una centralización en la gestión de las fronteras? Revista de Derecho Comunitario Europeo, 59, 143-186. Disponible en: https://doi.org/10.18042/cepc/rdce.59.04.

Soler García, C. (2017). La guardia europea de fronteras y costas: ¿un avance respecto a FRONTEX? Una valoración provisional. Revista Electrónica de Estudios Internacionales, 34, 4. Disponible en: https://doi.org/10.17103/reei.34.05. 